\title{
Prevention of coronary heart disease: the role of high density lipoproteins
}

\author{
N. E. Miller \\ M.D., Ch.B., M.Sc., Ph.D., M.R.C.Path \\ Department of Chemical Pathology and Metabolic Disorders, \\ St Thomas' Hospital Medical School, London
}

\begin{abstract}
Summary
There is now strong evidence that the risk of developing clinical coronary heart disease (CHD) in apparently healthy middle-aged men is inversely related to the plasma high density lipoprotein (HDL) cholesterol concentration. This reflects an underlying relationship between HDL cholesterol concentration and the severity of coronary atherosclerosis.

This new information represents a significant development in atherosclerosis research. In the author's opinion, however, it is not yet justifiable, or indeed possible, to utilize this knowledge in CHD prevention programmes for 3 reasons. Firstly, there is still little prospective information on HDL and CHD in women, in younger subjects and in patients with existing clinical disease. Secondly, although there are at least 2 working hypotheses, a causal relationship between HDL metabolism and atherogenesis has not yet been established. Thirdly, there is still a relative paucity of information on the environmental determinants of HDL concentration and metabolism. Thus, premature attempts at intervention in an uncontrolled manner, and particularly the use of drugs for an HDLraising effect, might only confuse the issue. While further research is being undertaken, attention should continue to be directed towards other reversible coronary risk factors (including hypercholesterolaemia, hypertension, and cigarette smoking) in CHD prevention programmes.
\end{abstract}

\section{Introduction}

Of the 4 major lipoprotein classes of plasma
(Table 1), the high density, or alpha, lipoproteins (HDL) had until recently received the least attention. Composed mostly of specific proteins and phospholipid, HDL makes only a minor contribution to the plasma total cholesterol (usually $<25 \%$ ) and triglyceride (usually $<10 \%$ ) concentrations, and is also more difficult to isolate and quantify than the other classes. Although case-control studies in the 1950 s had repeatedly documented low mean HDL cholesterol concentrations in coronary heart disease (CHD) victims, the 'infiltration theory' of atherogenesis, based largely on animal experiments, had polarized thought to such an extent that the phenomenon was overlooked, or disregarded as being of no pathological significance.

\section{HDL cholesterol, CHD and atherosclerosis}

Miller and Miller (1975) examined the clinical and epidemiological literature relating to HDL, and concluded that there was no good reason to exclude a role of HDL metabolism in atherogenesis: the association of low HDL cholesterol concentrations with clinical CHD was striking in its consistency and warranted further investigation as a coronary risk factor. As a working hypothesis, they proposed that a low HDL cholesterol concentration is indicative of inefficient cholesterol transport from peripheral tissues, including arterial smooth muscle. There was already evidence that HDL might be the primary acceptor of cellular cholesterol (Glomset, 1970).

During the past 5 years a body of data has

TABLE 1. The major plasma lipoproteins

\begin{tabular}{|c|c|c|c|}
\hline Lipoprotein class & Density $(\mathrm{g} / \mathrm{ml})$ & $\begin{array}{c}\text { Electrophoretic } \\
\text { mobility } \\
\text { (on paper) }\end{array}$ & $\begin{array}{l}\text { Major lipid } \\
\text { component(s) }\end{array}$ \\
\hline Chylomicrons & $<0.95$ & None & $\begin{array}{l}\text { Glyceride } \\
\text { (exogenous) }\end{array}$ \\
\hline Very low density lipoprotein & $0.95-1.006$ & Pre- $\beta$ & $\begin{array}{l}\text { Glyceride } \\
\text { (endogenous) }\end{array}$ \\
\hline Low density lipoprotein & $1 \cdot 006-1 \cdot c j 3$ & $\beta$ & Cholesterol ester \\
\hline High density lipoprotein & $1 \cdot 063-1 \cdot 21$ & $\alpha$ & $\begin{array}{l}\text { Phospholipid } \\
\text { Cholesterol ester }\end{array}$ \\
\hline
\end{tabular}


accumulated which leaves little doubt that in apparently healthy middle-aged men CHD risk is inversely related to the plasma HDL cholesterol level. The relationship appears to be statistically independent of other plasma lipoprotein levels, and to apply to both major categories of CHD (angina, myocardial infarction). The evidence relating HDL cholesterol to clinical CHD has been provided principally by 2 prevalence studies, the Honolulu Study (Rhoads, Gulbrandsen and Kagan, 1976) and the Cooperative Lipoprotein Phenotyping Study (Castelli et al., 1977) and by 3 prospective studies: the Tromsø Heart Study in Norway (Miller et al., 1977), the Framingham Study in the

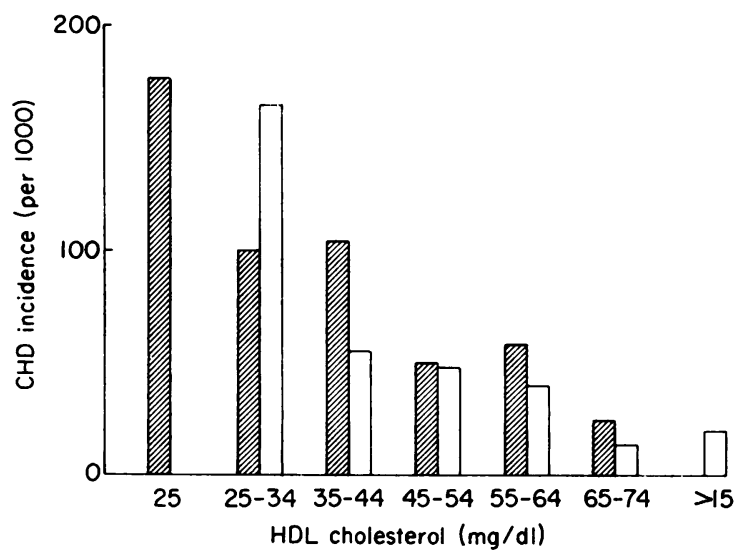

FIG. 1. Incidence of coronary heart disease (CHD) as a function of HDL cholesterol concentration in the Framingham Study (Gordon et al., 1977). Males; $\square$ females.

United States (Gordon et al., 1977) (Fig. 1), and the Israeli Ischemic Heart Disease Study (Goldbourt and Medalie, 1979) (Fig. 2). Evidence that these findings reflect an underlying relationship between HDL cholesterol and the severity of coronary atherosclerosis has been provided by angiographic studies (Pearson et al., 1979; Jenkins, Harper and Nestel, 1978; Moore et al., 1979). In all of these studies the predictive power of HDL cholesterol concentration for clinical or angiographic disease was at least as great as that of the plasma total cholesterol concentration.

High density lipoprotein is composed of at least 2 populations of particles: $\mathrm{HDL}_{2}$ of density 1.063$1 \cdot 125 \mathrm{~g} / \mathrm{ml}$, and $\mathrm{HDL}_{3}$ of density $1 \cdot 125-1 \cdot 21 \mathrm{~g} / \mathrm{ml}$. The former has the greater cholesterol/protein ratio, but usually accounts for only a minor proportion of total HDL cholesterol. It has long been

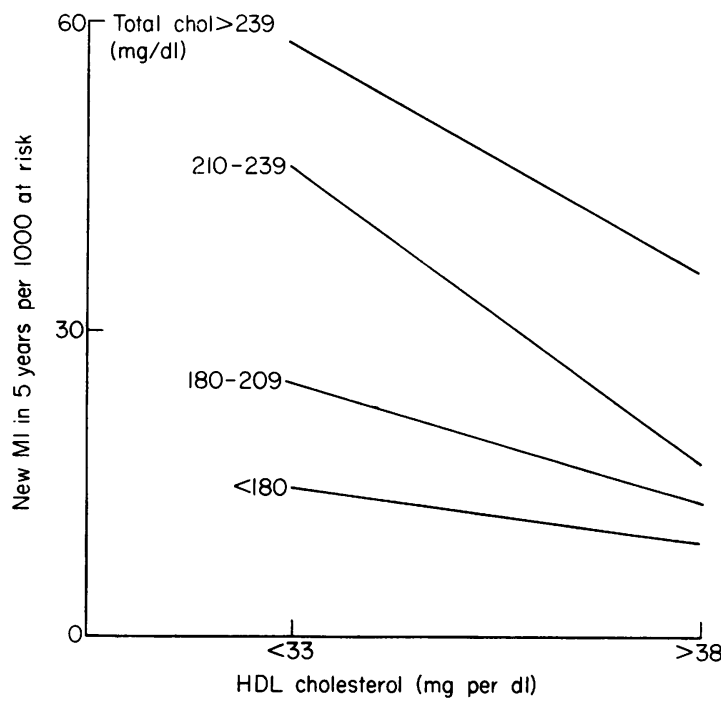

FIG. 2. Incidence of myocardial infarction (MI) as a function of the plasma total and HDL cholesterol concentrations in men aged 40 years or more in the Israeli Ischemia Heart Disease Study (Goldbourt and Medalie, 1979).

established that the lower mean HDL cholesterof concentration in men relative to that in premenos pausal women reflects a proportionately greater reduction of $\mathrm{HDL}_{2}$ than of $\mathrm{HDL}_{3}$. In view of this observation the author and his colleagues have recently examined the separate relationships of $\mathrm{HDL}_{2}$ and $\mathrm{HDL}_{3}$ cholesterol to coronary atherosclerosis. In a study of mostly middle-aged men with suspected myocardial ischaemia, increasing severity of coronary atherosclerosis (quantified by angiography) was associated with a significant decrease in the $\mathrm{HDL}_{2} / \mathrm{HDL}_{3}$ ratio (Hammett et al., 1979). A 10-year follow-up study by Gofman and Tandy in 1967 had already provided evidence for low HDL concentrations (quantified by analytical ultracentrifugation) in subjects destined to develop CHD, but this was not considered to be significant at the time.

\section{HDL and coronary prevention}

A major issue for debate is whether or not we are yet in a position to apply this new knowledge concerning HDL in community-wide CHD prevention programmes. It is the author's opinion that we have not reached this stage. This conclusion is based in 0 particular on a consideration of: (1) a number of deficiencies in the currently available data; (2) the absence of unequivocal evidence that the epidemiological correlation is causal; and (3)the relative paucity of information at present on the 
environmental determinants of HDL concentration and metabolism. The remainder of this article will be devoted to a discussion of these issues.

An examination of the 3 major prospective studies relating to HDL cholesterol concentration reveals that there is a paucity of information on females (included only in the Framingham Study (Gordon et al., 1977), on subjects below the age of 40 years (included only in the Tromsø Study (Miller et al., 1977), and on subjects with existing clinical CHD. The evidence is strong that a low HDL cholesterol level is a marker of increased susceptibility to CHD in apparently healthy men aged $\mathbf{4 0}$ years and more, but more information is needed in other groups.

In attempting to assess the significance and nature of any epidemiological relationship it is useful to search for situations in which the correlation does not appear to hold. There are at least 2 disorders of lipoprotein metabolism in which a low HDL cholesterol level may not be associated with increased susceptibility to CHD: familial lipoprotein lipase deficiency and familial hypertriglyceridaemia (Brunzell et al., 1976). Similarly, there are ethnic groups, such as the Maasai in East Africa (Robinson, Williams and Day, 1979) who appear to possess a low mean HDL cholesterol level, but who nevertheless also have a low CHD incidence. Although susceptiblity to CHD appears to be increased in familial HDL deficiency (Tangier disease), it is probably not increased to the extent that would be anticipated on the basis of the epidemiological relationships (Assmann, 1978).

Although such apparent inconsistencies might merely reflect a coincidental absence of other risk factors (most of the above situations are, for example, associated also with low plasma LDL (low density lipoprotein) cholesterol concentrations), they raise the possibility that the HDL-CHD relationship is not a simple one.

Perhaps the most important consideration in the present context, however, is the present lack of evidence for a causal relationship between HDL metabolism and atherogenesis. The original working hypothesis (Miller and Miller, 1975), that the plasma HDL cholesterol concentration is a reflection of the efficiency of cholesterol transport mechanisms from peripheral tissues by virtue of a role of HDL or its precursors in that process, has already been mentioned. Although supported by more recent studies, this concept remains unproved. So also does the suggestion that HDL may retard the uptake of LDL by arterial smooth muscle cells (Carew et al., 1976). Consistent with both concepts is the evidence that the rate of accumulation of tissue cholesterol varies inversely with the plasma HDL cholesterol concentration (Miller, Nestel and Clifton-Bligh, 1976; Nestel and Miller, 1980).
Finally, a review of the literature concerning possible environmental determinants of HDL concentration indicates that we are not yet in a position to intervene, even if the relationship were shown to be causal. Much of the available data are cross-sectional in nature, and what information has been provided by longitudinal (i.e. intervention) studies has not always been consistent. Thus, although physically very active individuals (e.g. marathon runners) have been clearly shown to have higher HDL concentrations than inactive subjects (Wood et al., 1976), the effects of physical training programmes on HDL cholesterol have not been consistent. Similarly, although an inverse relationship between HDL cholesterol concentration and adiposity has been demonstrated in population studies (Williams, Robinson and Bailey, 1979), no clear picture has yet emerged of the effects of weight reduction on HDL cholesterol. In crosssectional data HDL cholesterol also decreases with increasing cigarette consumption (Williams et al., 1979; Garrison et al., 1978), but at present there is no information on the effects of cessation of cigarette smoking on HDL cholesterol concentration. Crosssectional and longitudinal studies have provided concordant results to show that HDL cholesterol is reduced by dietary carbohydrate (Wilson and Lees, 1972; Rhoads, Kagan and Yano, 1976) and is increased by alcohol (Williams et al., 1979; Berg and Johansson, 1973), but the nature and mechanism of these changes has yet to be established. It is possible that alterations in HDL concentration induced by environmental factors might have different consequences in relation to CHD according to whether they result from changes in the synthesis or catabolism of the lipoprotein.

Multiple regression analyses of population data, have suggested that there are major determinants of the plasma HDL cholesterol level which remain to be identified (Hulley, Cohen and Widdowson, 1977; Førde et al., 1978). Twin studies have indicated that these are unlikely to be genetic (Feinleib et al., 1977). Some of them are certain to be dietary, and there is a particular paucity of information in this area. What little information is available suggests that dietary cholesterol increases HDL concentration slightly (Applebaum-Bowden et al., 1979; Mistry et al., 1976) and that diets of very high linoleic acid content may have the opposite effect (Shepherd et al., 1978). There is less information concerning the effects of moderate intakes of unsaturated fat, and this is clearly an area for future research.

\section{References}

Applebaum-Bowden, D., Hazzard, W.R., Cain, J., Cheung, M.C., Rampratap, S.K. \& Albers, J.J. (1979) Short-term egg-yolk feeding in humans. Atherosclerosis, 33, 385. 
Assmann, G. (1978) The metabolic role of high density lipoproteins: perspectives from Tangier disease. In: High Density Lipoproteins and Atherosclerosis. (Ed by Gotto, A.M., Miller, N.E. and Oliver, M.F.) pp. 77-89. Elsevier, Amsterdam.

BERG, B. \& JohANSSON, B.G. (1973) Effects of alcohol on parameters of liver function, plasma lipid concentrations and lipoprotein patterns. Acta medica scandinavica, 552 (Suppl.), 13.

Brunzell, J.D., SchrotT, H.G., Motulsky, A.G. \& BIERMAN, E.L. (1976) Myocardial infarction in familial forms of hypertriglyceridemia. Metabolism, 25, 313.

Carew, T.E., Koschinsky, T., Hayes, S.B. \& Steinberg, D. (1976) A mechanism by which high density lipoproteins may slow the atherogenic process. Lancet, i, 1315.

Castelli, W.P., Doyle, J.T., Gordon, T., Hames, C.G., Huortland, M.C., Hulley, S.B., Kagan, A. \& Zukel, W.J. (1977) HDL cholesterol and other lipids in coronary heart disease. The Cooperative Lipoprotein Phenotyping Study. Circulation, 55, 767.

Feinleib, M., Garrison, R.J., Fabsitz, R., Christian, J.C., Hrubec, Z., Borhani, N.O., Kannel, W.B., Rosenman, R., Schwartz, J.T. \& Wagner, J.O. (1977) The NHLBI twin study of cardiovascular disease risk factors: methodology and summary of results. American Journal of Epidemiology, 106, 284.

Førde, O.H., Thelle, D.S., Miller, N.E. \& Muøs, O.D. (1978) The Tromsø Heart Study. Distribution of serum cholesterol between high density and lower density lipoproteins in subjects of Norse, Finnish and Lappish ethnic origin. Acta medica scandinavica, 203, 21.

Garrison, R.J., Kannel, W.B., Feinleib, M., Castelli, W.P., McNamara, P.M. \& PadgetT, S.J. (1978) Cigarette smoking and HDL cholesterol. Atherosclerosis, 30, 17.

Glomset, J.A. (1970) Physiological role of lecithin: cholesterol acyltransferase. American Journal of Clinical Nutrition, 23, 1129.

GofmaN, J.W. \& TANDY, R.K. (1967) Lipid transport in hyperlipidaemia. In: Atherosclerotic Vascular Disease. (Ed. by Brest, A.N. and Moyer, J.H.) pp. 162-187. Butterworths, London.

Goldbourt, U. \& Medalie, J.H. (1979) High density lipoprotein cholesterol and incidence of coronary heart disease-the Israeli Ischemic Heart Disease Study. American Journal of Epidemiology, 109, 296.

Gordon, T., Castelli, W.P., HJortland, M.C., Kannel, W.B. \& DAWBER, T.R. (1977) High density lipoprotein as a protective factor against coronary heart disease. American Journal of Medicine, 62, 707.

Hammett, F., SAltissi, S., Miller, N., Rao, S., VanZeller, H., Coltart, J. \& Lewis, B. (1979) Relationship of coronary atherosclerosis to plasma lipoproteins. Circulation, 59/60 (Suppl. 2), (abstr, no. 651) 167.

Hulley, S.B., CoHen, R. \& Widdowson, G. (1977) Plasma high density lipoprotein cholesterol level. Influence of risk factor intervention. Journal of the American Medical Association, 238, 2269.
Jenkins, P.J., Harper, R.W. \& Nestel, P.J. (1978) Severity of coronary atherosclerosis related to lipoprotein concentration. British Medical Journal, 2, 388.

Miller, G.J. \& Miller, N.E. (1975) Plasma high density lipoprotein concentration and development of ischaemic heart disease. Lancet, i, 16

Miller, N.E., Førde, O.H., Thelle, D.S. \& Muøs, O.D. (1977) The Tromsø Heart Study. High density lipoprotein and coronary heart disease: a prospective case-control study. Lancet, i, 965.

Miller, N.E., Nestel, P.J. \& Clifton-Bligh, P. (1976) Relationships between plasma lipoprotein cholesterol concentrations and the pool size and metabolism of cholesterol in man. Atherosclerosis, 23, 535.

Mistry, P., Nicoll, A., Niehaus, C., Chrystie, I., JANUS, J. \& LEwIs, B. (1976) Cholesterol feeding revisited. Circulation, 53/54 (Suppl. 2), (abstr. 0696) 178.

Moore, R.B., Long, J.M., Matts, J.P., Amplatz, K., VARCo, R.L., BUCHWALD, H. \& THE POSCH GROUP (1979) Plasma lipoproteins and coronary arteriography in subjects in the program on the surgical control of the hyperlipidemias. Atherosclerosis, 32, 101.

Nestel, P.J. \& Miller, N.E. (1980) Cholesterol kinetics and fecal steroid excretion in subjects with primary hyperalphalipoproteinemia. Atherosclerosis, 36, 127.

Pearson, T.A., Bulkley, B.H., AChuff, S.C., Kwiterovich, P. \& GoRDIs, L. (1979) The association of low levels of HDL cholesterol and arteriographically defined coronary artery disease. American Journal of Epidemiology, 109, 285.

Rhoads, G.G., Gulbrandsen, C.L. \& Kagan, A. (1976) Serum lipoproteins and coronary heart disease in a population study of Hawaii Japanese men. New Englana Journal of Medicine, 294, 293.

RhoAds, G.G., Kagan, A. \& Yano, K. (1976) Associations between dietary factors and plasma lipoproteins. Cine culation, 53/54 (Suppl. 2), 53.

Robinson, D., Williams, P. \& DAY, J. (1979) High density lipoprotein cholesterol in the Maasai of East Africa: a cautionary note. British Medical Journal, 1, 1249.

Shepherd, J., Packard, C.J., Patsch, J.R., Gotto, A.M. \& TAUNTON, O.D. (1978) Effects of dietary polyunsaturated and saturated fat on the properties of high density lipoproteins and the metabolism of apolipoprotein AI. Journal of Clinical Investigation, 61, 1582.

Williams, P., Robinson, D. \& Bailey, A. (1979) High density lipoprotein and coronary risk factors in normal man. Lancet, i, 72.

WILSON, D.E. \& LEES, R.S. (1972) Metabolic relationships among the plasma lipoproteins. Reciprocal changes in the concentrations of very low density and low density lipoproteins in man. Journal of Clinical Investigation, 51, 1051.

Wood, P.D., Haskell, W., Klein, H., Lewis, S., Stern, M.P. \& FARQuHAR, J.W. (1976) The distribution of plasma lipoproteins in middle-aged male runners. Metabolism, 25, 1249. 